\title{
BMI open Myocardial infarction incidence and survival by ethnic group: Scottish Health and Ethnicity Linkage retrospective cohort study
}

To cite: Bansal N, Fischbacher CM, Bhopal RS, et al. Myocardial infarction incidence and survival by ethnic group: Scottish Health and Ethnicity Linkage retrospective cohort study. BMJ Open 2013;3:e003415. doi:10.1136/bmjopen-2013003415

- Prepublication history and additional material for this paper is available online. To view these files please visit the journal online (http://dx.doi.org/10.1136/ bmjopen-2013-003415)

Received 18 June 2013 Accepted 26 July 2013

${ }^{1}$ Public Health Sciences, Centre for Population Health Studies, University of Edinburgh,Edinburgh, UK ${ }^{2}$ Information Services Division, NHS National Services Scotland, Edinburgh, UK ${ }^{3}$ Division of Public Health, University of Liverpool, Liverpool, UK

Correspondence to Dr Colin M Fischbacher; Colin.Fischbacher@nhs.net

\author{
Narinder Bansal, ${ }^{1}$ Colin M Fischbacher, ${ }^{2}$ Raj S Bhopal, ${ }^{1}$ Helen Brown, ${ }^{1}$ \\ Markus FC Steiner, ${ }^{1}$ Simon Capewell, ${ }^{3}$ on behalf of the Scottish Health \\ and Ethnicity Linkage Study
}

\section{ABSTRACT}

Objective: Inequalities in coronary heart disease mortality by country of birth are large and poorly understood. However, these data misclassify UK-born minority ethnic groups and provide little detail on whether excess risk is due to increased incidence, poorer survival or both.

Design: Retrospective cohort study.

Setting: General resident population of Scotland. Participants: All those residing in Scotland during the 2001 Census were eligible for inclusion: 2972120 people were included in the analysis. The number still residing in Scotland at the end of the study in 2008 is not known.

Primary and secondary outcome measures: As specified in the analysis plan, the primary outcome measures were first occurrence of admission or death due to myocardial infarction and time to event. There were no secondary outcome measures.

Results: Acute myocardial infarction (AMI) incidence risk ratios $(95 \% \mathrm{Cls})$ relative to white Scottish populations (100) were highest among Pakistani men (164.1 (142.2 to 189.2)) and women (153.7 (120.5, 196.1)) and lowest for men and women of Chinese (39.5 (27.1 to 57.6) and 59.1 (38.6 to 90.7)), other white British (77 (74.2 to 79.8 ) and 72.2 (69.0 to 75.5)) and other white (83.1 (75.9 to 91.0$)$ and 79.9 (71.5 to 89.3)) ethnic groups. Adjustment for educational qualification did not eliminate these differences. Cardiac intervention uptake was similar across most ethnic groups. Compared to white Scottish, 28-day survival did not differ by ethnicity, except in Pakistanis where it was better, particularly in women (0.44 (0.25 to 0.78)), a difference not removed by adjustment for education, travel time to hospital or cardiac intervention uptake.

Conclusions: Pakistanis have the highest incidence of AMI in Scotland, a country renowned for internationally high cardiovascular disease rates. In contrast, survival is similar or better in minority ethnic groups. Clinical care and policy should focus on reducing incidence among Pakistanis through more aggressive prevention.

\section{ARTICLE SUMMARY}

Strengths and limitations of this study

- The overall size (4.65 million people), the availability of an ethnic code completed by the householder on behalf of the household or by individuals; information on a wide range of ethnic groups; the linkage of census data to both hospital morbidity and community/hospital mortality so that differences in hospitalisation do not just reflect community mortality; and the linkage of travel time data. Audits show high completeness $(99 \%)$ and quality $(94 \%$ diagnostic coding accuracy) of the SMR01 file for coronary heart disease diagnoses. All deaths are certified by a doctor in Scotland and all public hospitals are required to submit data. The private hospital sector is small in Scotland. The validity of available indicators of socioeconomic position is not yet established in multiethnic studies. These data break new ground in Europe, both in terms of findings and in linkage methods.

- The small population size for some non-White populations and therefore small number of events and imprecision of estimates as well as aggregation of data for heterogeneous ethnic groups such as African and Caribbean; the inability to capture events that may have occurred outside the UK; the unavailability of linkable CVD risk factor data; the unavailability of reliable diabetes data from SMR01 records; and the unavailability of data on acute myocardial infarction stage and severity and time to treatment.

\section{INTRODUCTION}

Coronary heart disease (CHD) dominates as the leading cause of premature mortality worldwide $^{1}$ and has been shown to vary by country of birth in Europe and North America. ${ }^{2}{ }^{3}$ Residents of England and Wales born in the Indian subcontinent (South Asians) for example, have higher mortality from CHD than most other minority ethnic 
groups, including people of European ancestry, ${ }^{4}$ a pattern observed globally. ${ }^{2}{ }^{5}$ Such findings are surprising given the high rates of disease in Northern Europe. In Scotland, where CHD is notoriously common, there were small differences in CHD mortality between those born in Scotland and those born in India and Pakistan, reflecting the high rate in the Scotland-born reference population. ${ }^{6}$ Estimates of ethnic variations in risk are usually based on country of birth and mortality rates. However, the increase in the locally born minority ethnic populations, and the fact that large numbers of older White people may be born abroad, for example, in India during colonial times, makes country of birth an inaccurate guide to ethnic group variations, particularly in the youngest and oldest age groups. Furthermore, whether mortality variations are attributable to increased incidence, poorer survival or both, has not been well researched. ${ }^{7}$ This is a drawback of most of the available research.

Ethnicity data are needed to determine best treatment strategies and assess the overall health of ethnically diverse populations. Internationally, the need for data on the health of minority ethnic and racial groups is driven by policy and legislation responding to rapidly increasing ethnic diversity. ${ }^{8}$ These needs require national datasets covering the major diseases of which circulatory disorders are invariably dominant.

Our retrospective Scottish Health and Ethnicity Linkage Study uses linked data to investigate ethnic variations in health. ${ }^{9}$ We reported from a pilot (phase 1) project on the incidence of hospitalisation or death (in hospital or community) from acute myocardial infarction (AMI) and subsequent survival (from April 2001 to December 2003) in South Asians (there were insufficient numbers to disaggregate as Indians, Pakistanis and Bangladeshis). We found a $45 \%$ and $85 \%$ higher incidence of AMI in South Asian men and women, respectively, but better survival (HR 0.59) compared to non-South Asians. ${ }^{7}$

Expanding on our pilot, we present data from phase 2 of our study on first AMI incidence and survival by comparing ethnic groups in Scotland as defined by the 2001 Scottish Census categories. The aims of these analyses were to expand on and test hypotheses generated by phase 1 work by establishing risk status for each ethnic group in relation to the white Scottish. Particularly, we examined whether the heterogeneity in cardiovascular risk previously demonstrated within South Asian groups (Indian and Pakistani) $^{41011}$ is reflected in MI incidence and survival in Scotland. Second, given that Scottish migrants to England have comparatively high CHD relative to English-born populations, we aimed to compare the white Scottish with the other white British, white Irish and other white groups in Scotland. Third, we aimed to assess whether ethnic variations in survival are explained by differences in procedure use and proximity to hospital. Our prior hypotheses were that Indians and Pakistanis would have the highest, and Chinese the lowest, incidence of first AMI compared to the white Scottish population and that the better survival in South Asians demonstrated in phase 1 could be explained by decreased travel time to hospital. In the absence of local data on uptake of procedures by ethnic groups, we hypothesised from first principles based on previous research that minority ethnic groups would have a relatively decreased uptake of cardiac interventions. ${ }^{12}$

\section{METHODS}

Details of the methods have been published. ${ }^{7} 9{ }^{13}$ An anonymised dataset containing 2001 census (self-defined ethnicity and sociodemographic variables) and health data (hospital day case and inpatient discharge data and linked records of deaths in and out of hospital) was created using the probability linkage method. This created a file with the unique census identifier and the Scottish Community Health Index number (a national register of patients using the National Health Service). This file was used to link to hospital discharge/deaths data held in the Scottish Morbidity Record (SMR01) database. Approximately $95 \%$ of the 2001 Census population of 4.9 million was linked to health records overall (4.65 million, with $85 \%$ or more linked in every ethnic group).

This analysis was restricted to people $\geq 30$ years of age in April 2001, with a diagnosis of, or death (in or out of hospital) from, AMI between 1 May 2001 and 30 April 2008, and with no previous AMI recorded in the SMR01 database in the 10 years prior to the index event. AMI was identified using the International Classification of Diseases (ICD) 10th edition codes I21 and I22 (and using ICD 9th edition code 410 for the look-back period).

One category was selected by Census respondents from a list of 14 categories in response to the question 'What is your ethnic group?' The category labels are selfexplanatory. Owing to small numbers African, Caribbean, African Scottish or other African ethnic group categories were combined and are here referred to as the 'African' group. The 'Other South Asians' category includes the Bangladeshi group due to the low numbers of this population resident in Scotland. Travel times were calculated by estimating the off-peak drive time from postcode (zipcode) of patient to postcode of hospital attended or, in case of community death, nearest relevant hospital. Cardiac intervention uptake was defined as having an angioplasty (OPCS 4 code K49, K50.1, K75) or coronary artery bypass graft (K40-K46) any time prior to or within 28 days of, first AMI.

As described previously, ${ }^{14}$ we examined the relationship among eight indicators of socioeconomic position and all CVD rates. The indicators were: (1) the postcode (zipcode) based Scottish Index of Multiple Deprivation, (2) car ownership, (3) highest educational qualification of the individual, (4) highest educational qualification in the household, (5) National Statistics Socioeconomic 
Classification at individual and (6) household levels, (7) household tenure and (8) economic activity in the previous week. Individual educational level was selected as the most consistently associated measure. In every ethnic group the relative risk for all CVD deaths/hospitalisations for those with a higher qualification compared with no qualification was less than 1 (mostly about 0.8 ), and the $95 \%$ CI excluded 1 in 8/10 ethnic groups for men and $9 / 10$ groups in women. The other seven indicators were less consistent. Education varied by ethnic group. Education was used in analyses as a proxy for socioeconomic position (figure 1A,B).

The incidence (hospitalisation or death in or out of hospital) of first MI and survival (28-day) thereafter was compared between ethnic groups. The standard comparison population was the white Scottish population. We calculated directly standardised rates (DSR)/ 100 000/year by sex, and rate ratios; risk ratios (RRs) using Poisson regression with robust variance ${ }^{13}$; HRs using Cox regression; and 95\% CIs around summary measures. We multiplied rate and RRs by 100 for simplicity and presentation so that the reference population was 100 . The Poisson regression models were chosen due to their suitability for analysing frequency data, and the independent variables were selected in advance to test our prespecified hypotheses. ${ }^{13}$ The standard reference population was the white Scottish population. We adjusted DSR and rate ratios by age (10-year age groups), and RRs also for age and highest education status. No other confounders were included. We did not test for interaction given lack of power for analyses in most ethnic groups.

Case fatality data were adjusted for cardiac intervention uptake, education and off-peak travel times to hospital attended using Cox regression. Data were analysed using SAS V.9.

\section{Ethics and disclosure}

Ethical and other permissions and related issues have been reported in detail, ${ }^{7}{ }^{9}$ including an independent assessment by an ethicist. ${ }^{15}$ The analysis was conducted on a standalone computer in a locked room in the National Records of Scotland (formerly the General Register Office for Scotland) accessed only by named researchers (HB, $\mathrm{NB}$ and MFCS). We followed a strict protocol to prevent inadvertent disclosure of personal data including screening of outputs by an independent committee.

For the survival analyses, comparison of age- and education-adjusted and age-adjusted data for the restricted age cohort for which these data are available (30-74 years) are not shown here to prevent inadvertent disclosure of identity. For the same reason and due to the minimal effect of education on the HRs, the final model also excludes education.

\section{Focus of results}

The results text focuses on findings in which the 95\% CI for the rate, RR or HR does not include the reference value of the standard white Scottish comparison population (100 or 1) but the complete dataset is shown in tables.

\section{RESULTS}

AMI incidence of community mortality and hospitalisation mortality/discharge

There were 85150 first episodes of AMI in the linked population ( $\mathrm{n}=2972120)$ aged $\geq 30$ years between 2001 and 2008. As expected, the incidence of first AMI was higher for men than women in every age group (10-year categories; data not shown).

Tables 1 and 2 present the number of events, population, DSR and rate ratio with $95 \%$ CI by ethnic group for men and women. Tables 1 and 2 show that, compared to the white Scottish population, DSR and age-adjusted rate ratios were higher in Pakistani men and lower for other white British, other white and Chinese men and women. Indian, Pakistani and other South Asian populations were substantially different from each other. Among men, Pakistanis had the highest rates, followed by other South Asians and Indians. Among women, other South Asians had the highest rates, however the difference between Indian and Pakistani women was negligible. African men had the same rate as the white Scottish and the rates in the other Ethnic group and white Irish were also comparable to white Scottish men. White Irish women had similar rates to that of white Scottish women and the African and other Ethnic women shared similar rates. The Chinese group had the lowest rates and was the only group in which the absolute rates were lower in men than women. Chinese women had similar low rates compared to other white British women.

Figure 1A,B shows that adjustment for education did not remove these differences (figures restricted to cohort of individuals who have education data, 3074 years of age). This adjustment attenuated some, but not all, of the lower risk in the other white British (from 70.6 to 79.4 in men and from 61.2 to 69.8 in women) and other white (from 69.2 to 75.0 in men, and from 73.6 to 83.1 in women) group. In the Chinese group, adjustment for education resulted in lower RRs (from 36.1 to 33.9 in men, and from 52.6 to 48.5 in women) increasing the difference relative to the white Scottish. For Pakistani men, there was a slight attenuation of risk on education adjustment (from 168.2 to 162.2), whereas in Pakistani women, $20 \%$ of the excess was attenuated (from 162.2 to 143.1).

\section{Cardiac intervention uptake by ethnicity and sex}

Less than $1 \%$ of interventions occurred prior to MI. There was little ethnic variation in cardiac intervention rates in this cohort with a slightly higher intervention rate in the other white British compared to the white Scottish (figure 2). 
Figure 1 (A) First myocardial infarction age adjusted risk ratios with $95 \%$ Cl 1 May 2001 to 30 April 2008 in people $30-74$ years, by ethnic group and sex. (B) First myocardial infarction age and education adjusted risk ratios with $95 \% \mathrm{Cl} 1$ May 2001 to 30 April 2008 in people 30-74years, by ethnic group and sex.

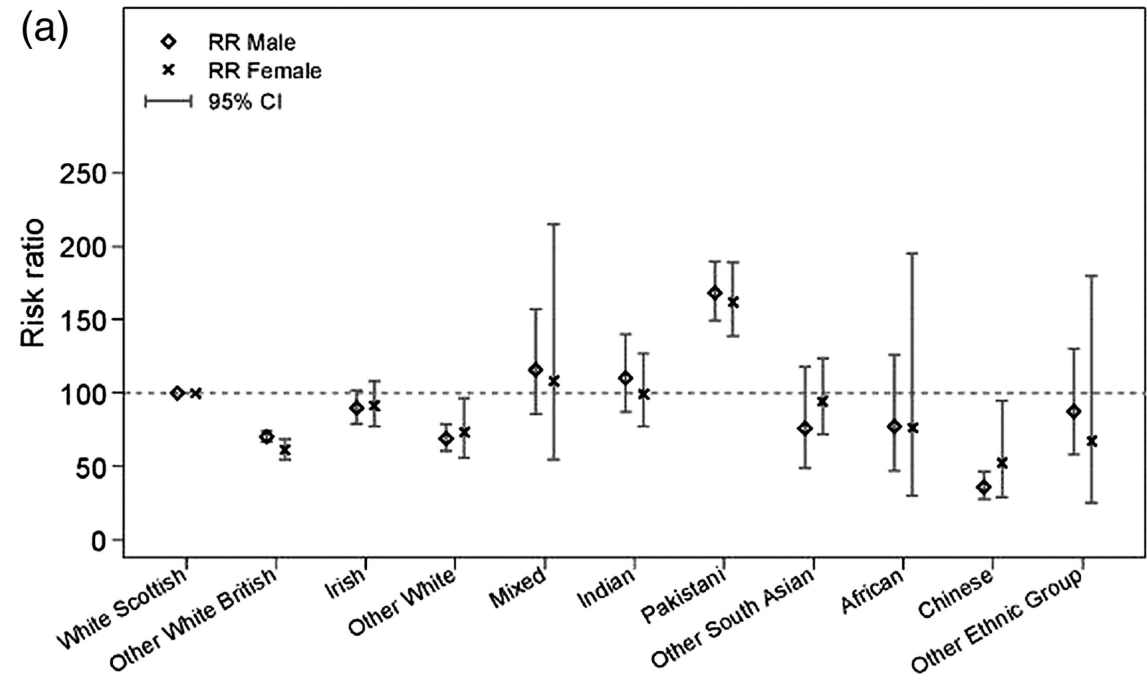

Ethnic Group

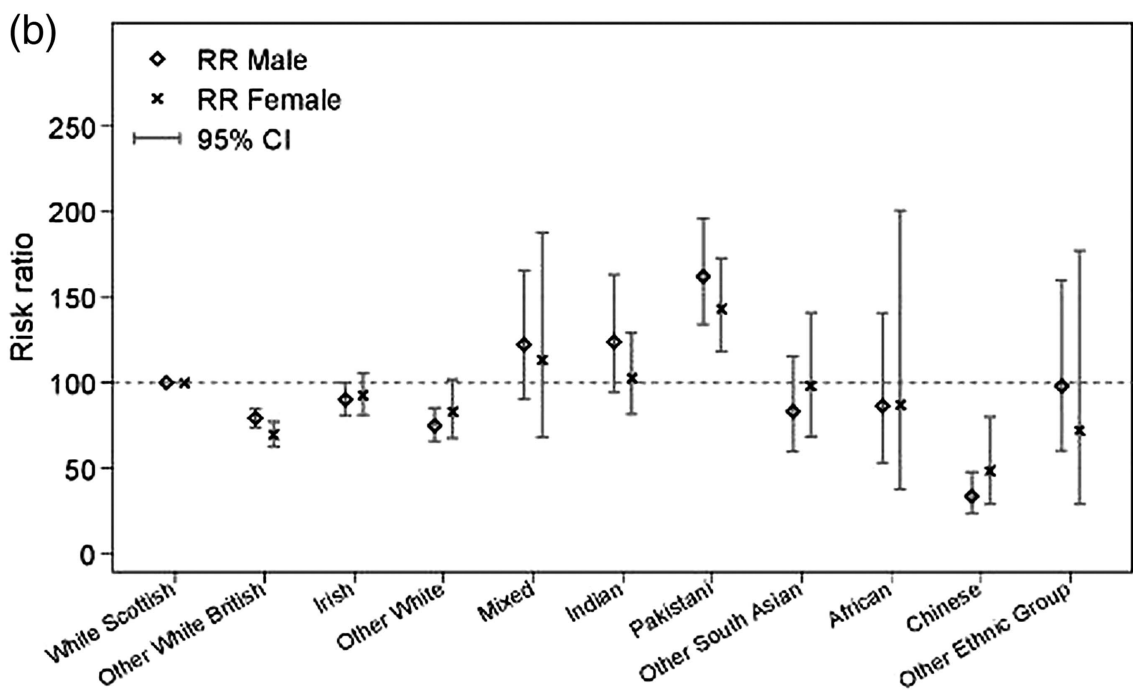

Ethnic Group
28 day survival and adjustment for age, travel time, cardiac intervention and education

Table 3 shows that compared to white Scottish men, age-adjusted HRs for death within 28 days of AMI were lower for other white British men. Lower HR in other white and Pakistani men are of note but the 95\% CI included 1 here. Table 4 shows that Pakistani women had substantially lower HR compared to white Scottish women. Further adjustment for hospital travel times, cardiac intervention uptake and education did not greatly change the interpretation of the results.

\section{DISCUSSION}

\section{Principal findings}

We found sizeable and important ethnic group variations in AMI incidence and survival. These data clearly demonstrate that the high cardiovascular mortality observed in South Asians, especially Pakistanis, mainly reflects increased incidence and not increased case fatality. Our data also demonstrate the reality of the predicted effects of previously reported heterogeneity in cardiovascular risk factors in Indians, Pakistanis and Bangladeshis. ${ }^{11}$ The highest rates were seen in Pakistani men, consistent with their pattern of risk factors and their high cardiovascular mortality data based on country of birth from England and Wales. This new analysis demonstrated more marked variations than that shown in country of birth data from Scotland, thereby demonstrating the specificity of ethnic group over country of birth. ${ }^{6}$ Mortality data based on country of birth have the problem of misclassification error which attenuates associations. ${ }^{16}$ We found higher risk in Scottish men and women compared to other non-Scottish white groups, particularly other white British (mostly English), a difference not removed by 
Table 1 First acute myocardial infarction directly standardised rates and rate ratios (per year, per 100 000) with $95 \% \mathrm{Cl} 1$ May 2001 to 30 April 2008 in people $\geq 30$ years, by ethnic group (men)

\begin{tabular}{|c|c|c|c|c|c|c|}
\hline \multirow{3}{*}{$\frac{\text { Ethnic grouplmen }}{\text { White Scottish }}$} & \multirow{3}{*}{$\frac{\text { Events (n) }}{43498}$} & \multirow{3}{*}{$\frac{(n)}{1212686}$} & \multirow{2}{*}{\multicolumn{2}{|c|}{$\begin{array}{l}\text { Directly standardised } \\
\text { rate* }^{*} \\
\text { Rate and } 95 \% \mathrm{Cl}\end{array}$}} & \multirow{2}{*}{\multicolumn{2}{|c|}{ Rate ratio and $95 \% \mathrm{Cl}$}} \\
\hline & & & & & & \\
\hline & & & 512.4 & 507.8 to 517.1 & 100.0 & \\
\hline Other white British & 3147 & 116076 & 394.9 & 381.4 to 408.3 & 77.1 & 74.3 to 79.8 \\
\hline White Irish & 569 & 15454 & 477.5 & 439.5 to 515.5 & 93.2 & 85.7 to 100.7 \\
\hline Other white & 473 & 17335 & 419.0 & 381.2 to 456.8 & 81.8 & 74.4 to 89.2 \\
\hline Any mixed background & 45 & 1400 & 658.5 & 476.0 to 841.0 & 128.5 & 92.9 to 164.2 \\
\hline Indian & 89 & 3125 & 620.9 & 485.6 to 756.3 & 121.2 & 94.7 to 147.6 \\
\hline Pakistani & 190 & 5354 & 729.5 & 609.2 to 849.9 & 142.4 & 118.9 to 165.9 \\
\hline Other South Asian & 35 & 1714 & 675.8 & 446.5 to 905.1 & 133.2 & 82.7 to 183.8 \\
\hline African & 26 & 1746 & 512.4 & 332.1 to 692.7 & 100.0 & 64.8 to 135.2 \\
\hline Chinese & 27 & 3004 & 230.9 & 127.5 to 334.3 & 45.1 & 24.9 to 65.2 \\
\hline Other ethnic group & 27 & 1848 & 496.9 & 243.9 to 749.9 & 97.0 & 47.6 to 146.4 \\
\hline
\end{tabular}

adjustment for education. We confirmed previously reported lower rates in Chinese. ${ }^{4} 6$ We found no evidence of important ethnic variations in cardiac intervention uptake, pointing to equality of access to these cardiac procedures in Scotland. In comparison to incidence, ethnic differences in survival were small with no evidence of worse outcomes in the Scottish minority ethnic population. The other white British cardiovascular advantage was also reflected in a slightly lower risk of death 28 days after AMI in men. Contrary to the excess risk of AMI, Pakistani women had much lower risk of dying within 28 days of first AMI.

\section{Strengths and limitations of the study}

The strength and limitations of this study have been discussed previously. ${ }^{14}$ The strengths include the overall size (4.65 million people), the availability of an ethnic code completed by the householder on behalf of the household or by individuals; information on a wide range of ethnic groups; the linkage of census data to both hospital morbidity and community/hospital mortality so that differences in hospitalisation do not just reflect community mortality ${ }^{7}$; and the linkage of travel time data. Audits show high completeness (99\%) and quality (94\% diagnostic coding accuracy) of the SMR01 file for CHD diagnoses. All deaths are certified by a doctor in Scotland and all public hospitals are required to submit data. The private hospital sector is small in Scotland. The validity of available indicators of socioeconomic position is not yet established in multiethnic studies. We have tested eight indicators and selected the best of these. Our methods were systematic and will be reported in more detail elsewhere. ${ }^{14}$ These data break new ground in Europe, both in terms of findings and in linkage methods.

The weaknesses of the study include the small population size for some non-white populations, and therefore small number of events and imprecision of estimates as

Table 2 First acute myocardial infarction directly standardised rates and rate ratios (per year, per 100000 ) with $95 \% \mathrm{Cl} 1$ May 2001 to 30 April 2008 in people $\geq 30$ years, by ethnic group (women)

\begin{tabular}{|c|c|c|c|c|c|c|}
\hline \multirow{3}{*}{$\begin{array}{l}\text { Ethnic group women } \\
\text { White Scottish }\end{array}$} & \multirow{3}{*}{$\frac{\text { Events (n) }}{33969}$} & \multirow{3}{*}{$\frac{\text { (n) }}{1408662}$} & \multirow{2}{*}{\multicolumn{2}{|c|}{$\begin{array}{l}\text { Directly standardised } \\
\text { rate* } \\
\text { Rate and } 95 \% \mathrm{Cl}\end{array}$}} & \multirow{2}{*}{\multicolumn{2}{|c|}{ Rate ratio and $95 \% \mathrm{Cl}$}} \\
\hline & & & & & & \\
\hline & & & 344.5 & 340.9 to 348.0 & 100.0 & \\
\hline Other white British & 2044 & 127256 & 249.4 & 238.9 to 260.0 & 72.4 & 69.3 to 75.6 \\
\hline White Irish & 490 & 17927 & 327.2 & 299.0 to 355.4 & 95.0 & 86.7 to 103.2 \\
\hline Other white & 315 & 21210 & 278.7 & 248.2 to 309.3 & 80.9 & 72.0 to 89.8 \\
\hline Any mixed background & 33 & 1849 & 414.0 & 277.8 to 550.2 & 120.2 & 80.6 to 159.7 \\
\hline Indian & 35 & 2825 & 425.5 & 277.1 to 573.9 & 123.5 & 80.4 to 166.6 \\
\hline Pakistani & 65 & 4963 & 445.3 & 306.1 to 584.6 & 129.3 & 88.8 to 169.7 \\
\hline Other South Asian & 23 & 1324 & 526.8 & 321.6 to 732.0 & 153.3 & 89.4 to 217.2 \\
\hline African & 16 & 1504 & 418.0 & 209.6 to 626.4 & 121.3 & 60.8 to 181.9 \\
\hline Chinese & 21 & 3250 & 245.6 & 135.6 to 355.6 & 71.3 & 39.4 to 103.2 \\
\hline Other ethnic group & 13 & 2248 & 417.5 & 197.9 to 637.2 & 121.2 & 57.4 to 185.0 \\
\hline
\end{tabular}


Figure 2 Cardiac intervention uptake age adjusted risk ratios with $95 \% \mathrm{Cl}$ by ethnic group.

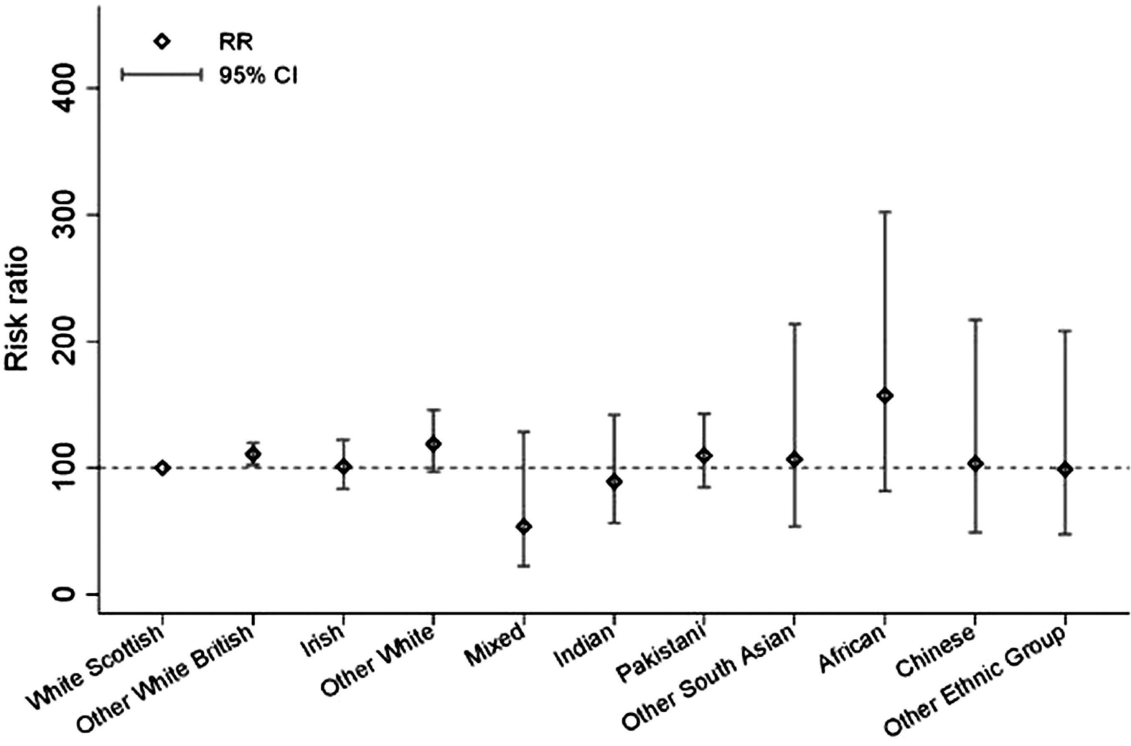

Ethnic Group well as aggregation of data for heterogeneous ethnic groups such as African and Caribbean; the inability to capture events that may have occurred outside the UK; the unavailability of data on time to treatment; the unavailability of linkable CVD risk factor data; the unavailability of reliable diabetes data from SMR01 records; and the unavailability of data on AMI stage and severity.

Findings in relation to the literature

The higher hospitalisation/death rates in white Scottish compared to other white groups are consistent with previous data comparing Scotland to England and Wales ${ }^{17}$ and Scottish-born people living in England and Wales to those born in England and Wales. Variation in AMI mortality by socioeconomic deprivation is well established ${ }^{1819}$ and has been demonstrated in Scotland. How much of Scotland's poorer health is accounted for by socioeconomic and lifestyle factors has so far been unclear. ${ }^{17}$ Consistent with previous data, ${ }^{20}$ we found that education was the socioeconomic factor most consistently associated with cardiovascular risk in all ethnic groups. Our data shows that the differences in risk between white groups remain even when education is taken into account.

Similarly, differences in risk in non-white groups were not explained by education. The lower cardiovascular risk in the Chinese is well known and may be attributable, in part, to lower risk factors such as smoking and alcohol consumption, ${ }^{21}$ lipids and BMI. ${ }^{22}$ However, not

Table 3 HR for death within 28 days of first MI by ethnic group (men)

\begin{tabular}{|c|c|c|c|c|c|c|}
\hline \multirow[b]{2}{*}{$\begin{array}{l}\text { Men ethnic } \\
\text { group }\end{array}$} & \multirow[b]{2}{*}{ Events } & \multirow[b]{2}{*}{$\mathbf{n}$} & \multicolumn{4}{|c|}{ Adjusted HR (95\% Cl) } \\
\hline & & & Age & $\begin{array}{l}\text { Age and travel } \\
\text { time }\end{array}$ & $\begin{array}{l}\text { Age and } \\
\text { intervention }\end{array}$ & $\begin{array}{l}\text { Age, travel time and } \\
\text { intervention }\end{array}$ \\
\hline White Scottish & 18730 & 43498 & 1.00 & 1.00 & 1.00 & 1.00 \\
\hline $\begin{array}{l}\text { Other white } \\
\text { British }\end{array}$ & 1298 & 3147 & 0.91 (0.86 to 0.96$)$ & $0.92(0.86$ to 0.98$)$ & $0.92(0.87$ to 0.97$)$ & $0.92(0.87$ to 0.98$)$ \\
\hline White Irish & 291 & 569 & $1.12(1.00$ to 1.26$)$ & $1.10(0.97$ to 1.24$)$ & $1.11(0.99$ to 1.25$)$ & $1.10(0.97$ to 1.24$)$ \\
\hline Other white & 202 & 473 & 0.89 (0.77 to 1.02$)$ & 0.91 (0.79 to 1.05$)$ & 0.91 (0.79 to 1.04$)$ & $0.93(0.80$ to 1.08$)$ \\
\hline $\begin{array}{l}\text { Any mixed } \\
\text { background }\end{array}$ & 21 & 45 & $1.08(0.70$ to 1.65$)$ & $1.12(0.72$ to 1.74$)$ & 1.01 (0.66 to 1.54$)$ & $1.06(0.69$ to 1.65$)$ \\
\hline Indian & 32 & 89 & $0.95(0.67$ to 1.35$)$ & $0.96(0.66$ to 1.38$)$ & 0.93 (0.66 to 1.32$)$ & 0.95 (0.66 to 1.37$)$ \\
\hline Pakistani & 51 & 190 & $0.81(0.61$ to 1.06$)$ & $0.86(0.65$ to 1.15$)$ & 0.81 (0.62 to 1.07$)$ & 0.87 (0.66 to 1.16$)$ \\
\hline $\begin{array}{l}\text { Other South } \\
\text { Asian }\end{array}$ & 11 & 35 & $0.74(0.41$ to 1.33$)$ & 0.72 (0.38 to 1.39$)$ & $0.76(0.42$ to 1.36$)$ & 0.77 (0.40 to 1.47$)$ \\
\hline African & 12 & 26 & $1.16(0.66$ to 2.04$)$ & $1.17(0.63$ to 2.18$)$ & $1.24(0.70$ to 2.18$)$ & $1.27(0.69$ to 2.37$)$ \\
\hline Chinese & 13 & 27 & $1.32(0.77$ to 2.28$)$ & $0.94(0.47$ to 1.89$)$ & 1.45 (0.84 to 2.49$)$ & $1.08(0.54$ to 2.17$)$ \\
\hline
\end{tabular}


Table 4 HR for death within 28 days of first MI by ethnic group (women)

\begin{tabular}{|c|c|c|c|c|c|c|}
\hline \multirow[b]{2}{*}{$\begin{array}{l}\text { Women ethnic } \\
\text { group }\end{array}$} & \multirow[b]{2}{*}{ Events } & \multirow[b]{2}{*}{$\mathbf{n}$} & \multicolumn{4}{|c|}{ Adjusted HR (95\% Cl) } \\
\hline & & & Age & $\begin{array}{l}\text { Age and travel } \\
\text { time }\end{array}$ & $\begin{array}{l}\text { Age and } \\
\text { intervention }\end{array}$ & $\begin{array}{l}\text { Age, travel time and } \\
\text { intervention }\end{array}$ \\
\hline White Scottish & 17159 & 33969 & 1.00 & 1.00 & 1.00 & 1.00 \\
\hline $\begin{array}{l}\text { Other white } \\
\text { British }\end{array}$ & 1032 & 2044 & $0.97(0.91$ to 1.03$)$ & 0.97 (0.91 to 1.04$)$ & 0.97 (0.91 to 1.03$)$ & $0.98(0.91$ to 1.04$)$ \\
\hline White Irish & 265 & 490 & 1.05 (0.93 to 1.19$)$ & 1.07 (0.94 to 1.21$)$ & 1.07 (0.94 to 1.20$)$ & $1.08(0.95$ to 1.23$)$ \\
\hline Other White & 161 & 315 & 1.01 (0.86 to 1.17$)$ & $1.03(0.88$ to 1.21$)$ & $1.01(0.87$ to 1.18$)$ & 1.04 (0.89 to 1.23$)$ \\
\hline $\begin{array}{l}\text { Any mixed } \\
\text { background }\end{array}$ & 16 & 33 & $0.98(0.60$ to 1.61$)$ & 0.96 (0.56 to 1.66$)$ & 0.93 (0.57 to 1.52$)$ & $0.92(0.53$ to 1.58$)$ \\
\hline Indian & 11 & 35 & $0.66(0.37$ to 1.19$)$ & $0.65(0.35$ to 1.20$)$ & $0.63(0.35$ to 1.13$)$ & $0.62(0.33$ to 1.15$)$ \\
\hline Pakistani & 12 & 65 & $0.44(0.25$ to 0.78$)$ & $0.44(0.24$ to 0.79$)$ & $0.44(0.25$ to 0.78$)$ & $0.44(0.25$ to 0.80$)$ \\
\hline $\begin{array}{l}\text { Other South } \\
\text { Asian }\end{array}$ & 13 & 23 & 1.19 (0.69 to 2.04$)$ & 1.24 (0.71 to 2.19$)$ & $1.15(0.67$ to 1.99$)$ & $1.22(0.69$ to 2.14$)$ \\
\hline African* & 7 & 16 & $0.91(0.43$ to 1.90$)$ & & & \\
\hline Chinese* $^{*}$ & 7 & 21 & $0.63(0.30$ to 1.31$)$ & & & \\
\hline
\end{tabular}

all risk factors are lower, for example, Chinese do not have the expected lower glucose intolerance despite their lower $\mathrm{BMI}^{23}$ and risk factor data from England show higher prevalence of diabetes and higher physical inactivity compared to the general population. ${ }^{24}$ More study is required in this group to explore protective factors and to see how incidence changes with subsequent generations and whether there is an expected convergence with UK rates.

Pakistanis, known to be at high cardiovascular risk, ${ }^{4} 10$ had a substantially elevated risk compared to the white Scottish. When differences in education were accounted for, Pakistanis had $40-60 \%$ higher risk of first MI. There has been much study and discussion exploring the potential role of complex biological and environmental factors and underlying pathways in the aetiology of the increased cardiovascular disease burden in South Asians. While the mechanisms underlying the excess risk remain to be elucidated, contrary to earlier accounts, it is becoming more evident that there is both a higher burden of major risk factors and fewer protective factors. $^{2} 112526$ Furthermore, considerable heterogeneity exists between specific South Asian groups (Indian, Pakistanis and Bangladeshis) both in risk factors and outcomes. ${ }^{411}$ A higher prevalence of smoking and low HDL is seen in Pakistani men compared to Indian, and a higher proportion of Pakistanis have been shown to be physically inactive and from a manual social class compared to Indians in England. ${ }^{24}$ Generational factors may also be important, although this has not been well explored. The relatively slow decline in cardiovascular mortality observed in Pakistani and Bangladeshi migrants in England and Wales ${ }^{10}$ strongly suggests less favourable changes in risk and protective factors, compared to other ethnic groups resident in England and Wales. Our data showing an excess of AMI incidence but no lesser cardiac intervention uptake and mortality after
AMI in Pakistanis in Scotland provides evidence for the presence of inequalities in prevention through identification and management of risk factors. However, inequalities in post-MI clinical management are not evident from our limited data, and information on other forms of clinical treatment is needed. Our findings are consistent with data from England showing equitable management of CHD in deprived groups, ${ }^{27}$ and specifically in South Asian patients. ${ }^{28}$

Our finding of better survival in Pakistani women is not unique to Scotland, it corroborates and adds to our previous analyses ${ }^{7}$ and to other studies in South Asians combined. ${ }^{29}$ Previous studies have not compared these heterogeneous South Asian groups separately, so this needs corroboration. Survival from first MI reflects severity and type of MI and access to, and timing of, treatment, including surgical management. We were unable to compare severity of MI, complications at presentation, or quality of medical care beyond cardiac interventions between ethnic groups. It may be that MI's in South Asians, especially Pakistani women, were less severe but this needs study. Reducing time to treatment reduces mortality. ${ }^{30}$ We did not have data on time to treatment as previously reported ${ }^{31}$ but distance from home to hospital of admission is a potentially important proxy for time to treatment. ${ }^{32}$ In our data, contrary to our hypothesis, adjustment for this proxy did not attenuate Pakistani women's advantage in survival.

Improvements in short-term survival following MI have been attributed to both medication and revascularisation. ${ }^{33}$ Some studies have reported ethnic inequalities in intervention uptake with lower use in South Asians. ${ }^{34}$ Notably, Feder et al's study showed major differences in cardiac intervention in Bangladeshis and Pakistanis. Consistent with data from the Whitehall study $^{36}$ and others $^{37}$ we found no evidence of less cardiac intervention in South Asians. 
Diabetes has been shown to contribute to poorer survival after MI in Scottish ${ }^{38}$ and South Asian patients 3839 and given the known higher prevalence in Indians and Pakistanis, our findings of survival being no worse after accounting for explanatory factors were unexpected. We were unable to consider the effect of diabetes in our analysis due to the incompleteness of diabetes recording in SMR01 datasets but this clearly needs further study.

Future work will explore linkage with the Scottish diabetes register and primary care records. There are no similar studies in other parts of Europe where minority ethnic populations are larger. There is no easy way of capturing events internationally, but deaths of UK residents are reported back via several channels, including embassies and consulates and the primary care registration systems. Such reports, however, may not provide the accurate cause of death.

\section{CONCLUSIONS}

The elevated AMI mortality in South Asians in Scotland principally reflects an increased incidence in Pakistanis. These findings emphasise the need for more aggressive clinical management of modifiable cardiovascular risk factors in this ethnic group. Pakistani women's lower case fatality was unexplained and not due to closer proximity to hospital or increased cardiac intervention uptake. Our data provide no evidence for important ethnic disparities in cardiovascular intervention uptake in Scotland. The disparity in risk between other white British and white Scottish is not merely explained by socioeconomic factors reflected by education. Given the limitations of country of birth data, cross-sectional analysis of mortality data, and the shortage of prospective multiethnic cohort studies in Europe, ${ }^{8}$ our retrospective cohort approach using self-defined ethnic group codes provides a promising approach to describing and understanding ethnic variations in cardiovascular disease. Clinical care and policy, therefore, now need to focus on reducing the number of cases through better prevention.

Acknowledgements The authors would like to thank the Scottish Chief Scientist's Office for funding this study, and NHS Health Scotland for a supplementary grant. The Equality and Diversity Information Programme of the Information Services Division (ISD) of NHS National Services Scotland and the National Records of Scotland both made 'in-house' contributions to the work. Joan Jamieson (ISD) was a co-investigator and general adviser. The researchers acted independently of the funding body and the study sponsor (the University of Edinburgh) at all stages of the work.

Collaborators Chris Povey had the idea of linking the census data to the data held by ISD and he performed most of the linkage work including developing methods. Jim Chalmers had the original idea for the use of one-way encryption. Ganka Mueller was key in linking census data to health data. Ms Genevieve Brin did the analysis of socioeconomic position. David Brewster and Kirsty MacLachlan have advised throughout. These important contributions did not meet ICMJE authorship requirements. The authorship and note of contributions has been agreed by all the investigators named.

Contributors NB was the lead writer and research fellow and co-ordinator of the study, RSB was the PI and CMF was co-PI and Chair of Cardiovascular sub-group of SHELS, HB and MFCS were the study statistician and data analyst, respectively. SC was a collaborator. All authors helped plan the study, evolve analysis plans, interpret data and critically revise successive drafts of the manuscript. NB and RSB are the guarantors.

Funding Scottish Chief Scientist Office grant (CZH/4/432).

\section{Competing interests None}

Ethics approval The work was approved by the Multicentre Research Ethics Committee (for Scotland) and the Privacy Advisory Committee of NHS National Services Scotland.

Provenance and peer review Not commissioned; externally peer reviewed.

Data sharing statement No additional data are available.

Open Access This is an Open Access article distributed in accordance with the Creative Commons Attribution Non Commercial (CC BY-NC 3.0) license, which permits others to distribute, remix, adapt, build upon this work noncommercially, and license their derivative works on different terms, provided the original work is properly cited and the use is non-commercial. See: http:// creativecommons.org/licenses/by-nc/3.0/

\section{REFERENCES}

1. Mackay J, Mensah G. The atlas of heart disease and stroke. Geneva: World Health Organization, 2004.

2. Anand SS, Yusuf S, Vuksan V, et al. Differences in risk factors, atherosclerosis, and cardiovascular disease between ethnic groups in Canada: the Study of Health Assessment and Risk in Ethnic groups (SHARE). Lancet 2000;356:279-84.

3. Yusuf S, Reddy S, Ounpuu S, et al. Global burden of cardiovascular diseases: part II: variations in cardiovascular disease by specific ethnic groups and geographic regions and prevention strategies. Circulation 2001;104:2855-64.

4. Wild SH, Fischbacher C, Brock A, et al. Mortality from all causes and circulatory disease by country of birth in England and Wales 2001-2003. J Public Health (Oxf) 2007;29:191-8.

5. Reddy KS, Yusuf S. Emerging epidemic of cardiovascular disease in developing countries. Circulation 1998;97:596-601.

6. Fischbacher CM, Steiner M, Bhopal R, et al. Variations in all cause and cardiovascular mortality by country of birth in Scotland, 19972003. Scott Med J 2007;52:5-10.

7. Fischbacher CM, Bhopal R, Povey C, et al. Record linked retrospective cohort study of 4.6 million people exploring ethnic variations in disease: myocardial infarction in South Asians. BMC Public Health 2007;7:142.

8. Rafnsson SB, Bhopal RS. Large-scale epidemiological data on cardiovascular diseases and diabetes in migrant and ethnic minority groups in Europe. Eur J Public Health 2009;19:484-91.

9. Bhopal R, Fischbacher C, Povey C, et al. Cohort profile: Scottish Health and Ethnicity Linkage Study of 4.65 million people exploring ethnic variations in disease in Scotland. Int J Epidemiol 2010.

10. Harding S, Rosato M, Teyhan A. Trends for coronary heart disease and stroke mortality among migrants in England and Wales, 1979-2003: slow declines notable for some groups. Heart 2008;94:463-70.

11. Bhopal R, Unwin N, White M, et al. Heterogeneity of coronary heart disease risk factors in Indian, Pakistani, Bangladeshi, and European origin populations: cross sectional study. BMJ 1999;319:215-20.

12. Bhopal R. Spectre of racism in health and health care: lessons from history and the United States. BMJ 1998;316:1970-3.

13. Bhopal RS, Bansal N, Steiner M, et al. Does the Scottish effect apply to all ethnic groups? All-cancer, lung, colorectal, breast and prostate cancer in the Scottish Health and Ethnicity Linkage Cohort Study. BMJ Open 2012;2:e001957.

14. Bhopal RS, Bansal N, Fischbacher C, et al. Ethnic variations in chest pain and angina in men and women: Scottish Ethnicity and Health Linkage Study of 4.65 million people. Eur J Cardiovasc Prev Rehabil 2011.

15. Boyd KM. Ethnicity and the ethics of data linkage. BMC Public Health 2007;7:318.

16. Gill PS, Kai J, Bhopal R, et al. Health care needs assessment: black and minority ethnic groups. The epidemiologically based needs assessment reviews. Radcliffe Medical Press Ltd, 2007.

17. Hanlon $\mathrm{P}$, Lawder RS, Buchanan D, et al. Why is mortality higher in Scotland than in England and Wales? Decreasing influence of socioeconomic deprivation between 1981 and 2001 supports the existence of a 'Scottish Effect'. J Public Health (Oxf) 2005;27:199-204. 
18. Morrison C, Woodward M, Leslie W, et al. Effect of socioeconomic group on incidence of, management of, and survival after myocardial infarction and coronary death: analysis of community coronary event register. BMJ 1997;314:541-6.

19. Capewell S, Maclntyre K, Stewart S, et al. Age, sex, and social trends in out-of-hospital cardiac deaths in Scotland 1986-95: a retrospective cohort study. Lancet 2001;358:1213-17.

20. Kelaher M, Paul S, Lambert $\mathrm{H}$, et al. The applicability of measures of socioeconomic position to different ethnic groups within the UK. Int J Equity Health 2009;8:4.

21. White M, Harland JO, Bhopal RS, et al. Smoking and alcohol consumption in a UK Chinese population. Public Health 2001; 115:62-9.

22. Harland JO, Unwin N, Bhopal RS, et al. Low levels of cardiovascula risk factors and coronary heart disease in a UK Chinese population. $J$ Epidemiol Community Health 1997;51:636-42.

23. Unwin N, Harland J, White $\mathrm{M}$, et al. Body mass index, waist circumference, waist-hip ratio, and glucose intolerance in Chinese and Europid adults in Newcastle, UK. J Epidemiol Community Health 1997;51:160-6.

24. Zaninotto P, Mindell J, Hirani V. Prevalence of cardiovascular risk factors among ethnic groups: results from the Health Surveys for England. Atherosclerosis 2007;195:e48-57.

25. Cruickshank JK, Cooper J, Burnett M, et al. Ethnic differences in fasting plasma C-peptide and insulin in relation to glucose tolerance and blood pressure. Lancet 1991;338:842-7.

26. Abate N, Chandalia M, Snell PG, et al. Adipose tissue metabolites and insulin resistance in nondiabetic Asian Indian men. J Clin Endocrinol Metab 2004;89:2750-5.

27. Bajekal M, Scholes S, Love $\mathrm{H}$, et al. Analysing recent socioeconomic trends in coronary heart disease mortality in England, 2000-2007: a population modelling study. PLoS Med 2012;9: e1001237.

28. Zaman MJ, Crook AM, Junghans C, et al. Ethnic differences in long-term improvement of angina following revascularization or medical management: a comparison between south Asians and white Europeans. J Public Health (Oxf) 2009;31:168-74.
29. Khan NA, Grubisic M, Hemmelgarn B, et al. Outcomes after acute myocardial infarction in South Asian, Chinese, and white patients. Circulation 2010;122:1570-7.

30. Boersma E, Maas AC, Deckers JW, et al. Early thrombolytic treatment in acute myocardial infarction: reappraisal of the golden hour. Lancet 1996;348:771-5.

31. Gupta M, Doobay AV, Singh N, et al. Risk factors, hospital management and outcomes after acute myocardial infarction in South Asian Canadians and matched control subjects. CMAJ 2002;166:717-22.

32. Wei L, Lang CC, Sullivan FM, et al. Impact on mortality following first acute myocardial infarction of distance between home and hospital: cohort study. Heart 2008;94:1141-6.

33. Briffa $\mathrm{T}$, Hickling $\mathrm{S}$, Knuiman $\mathrm{M}$, et al. Long term survival after evidence based treatment of acute myocardial infarction and revascularisation: follow-up of population based Perth MONICA cohort, 1984-2005. BMJ 2009;338:b36.

34. Sekhri N, Timmis A, Chen R, et al. Inequity of access to investigation and effect on clinical outcomes: prognostic study of coronary angiography for suspected stable angina pectoris. $B M$ 2008;336:1058-61.

35. Feder G, Crook AM, Magee P, et al. Ethnic differences in invasive management of coronary disease: prospective cohort study of patients undergoing angiography. BMJ 2002;324:511-6.

36. Britton A, Shipley M, Marmot M, et al. Does access to cardiac investigation and treatment contribute to social and ethnic differences in coronary heart disease? Whitehall II prospective cohort study. BMJ 2004;329:318.

37. Lear JT, Lawrence IG, Pohl JE, et al. Myocardial infarction and thrombolysis: a comparison of the Indian and European populations on a coronary care unit. J R Coll Physicians Lond 1994;28:143-7.

38. Capewell S, Livingston BM, Maclntyre K, et al. Trends in case-fatality in 117718 patients admitted with acute myocardial infarction in Scotland. Eur Heart J 2000;21:1833-40.

39. Wilkinson P, Sayer J, Laji K, et al. Comparison of case fatality in south Asian and white patients after acute myocardial infarction: observational study. BMJ 1996;312:1330-3. 